\title{
Tocotrienol-rich fractions (TRF) supplementation in school-going children with Attention Deficit/Hyperactive Disorder (ADHD): a randomized controlled trial
}

\author{
May Loong Tan ${ }^{1 *} \mathbb{D}$, Siew Cheng Foong ${ }^{1}$, Wai Cheng Foong ${ }^{1}$, Yusni Yusuff ${ }^{2}$ and Saralla M. Chettiar ${ }^{3}$
}

\begin{abstract}
Background: Attention Deficit/Hyperactive Disorder (ADHD) is often treated with medications but many parents seek alternative treatment for fear of adverse effects. Increased oxidative stress has been observed in children and adults with ADHD. We postulate that tocotrienol-rich fractions (TRF), a potent antioxidant from the natural Vitamin $E$ family, may help children with ADHD. The objective of this study is to determine if supplementation of TRF has an effect on the symptoms of school-going children with ADHD.

Methods: Children aged between 6 to 12 years with ADHD were randomized to TRF $200 \mathrm{mg}$ or placebo daily for 6 months. We measured the NICHQ Vanderbilt ADHD Parent (VAPRS) \& Teacher (VATRS) Rating Scales at baseline, 3 months and 6 months. Plasma tocotrienol levels were also measured at each of the corresponding time. We used ANOVA repeated measure and Spearman Rho's for analysis.

Results: One hundred forty-six children were randomized. The VAPRS showed significant improvement after 3 months and 6 months in both groups ( $n=73$ each). The VATRS revealed greater improvement in the TRF group but was not statistically significant $(p=0.07)$. The TRF group had higher levels of tocotrienols compared with the placebo group at 3 and 6 months. There was a small but significant correlation of the alpha and gamma tocotrienol levels with the change in VAPRS after 6 months.
\end{abstract}

Conclusion: TRF was not more effective than placebo in reducing the ADHD symptoms as measured by the VAPRS and VATRS. Possible reasons for this include placebo-effects and supplementations given too late in life. Future studies should consider using an objective outcome measurement (e.g. measuring attention-span) as well as earlier age of supplementation.

Trial registration: ClinicalTrials.gov NCT01855984, date of registration 10 May 2013.

Keywords: ADHD, Tocotrienols, Tocotrienol-rich fractions, Children, Antioxidant, Supplements

\section{Background}

Attention Deficit/Hyperactive Disorder (ADHD) is the commonest behavioural problem affecting school-going children [1]. It is estimated that $5-12 \%$ of school aged children have ADHD [2] and accounts for up to $50 \%$ of referrals to Paediatric Psychiatric services [3]. Current guidelines recommend the use of medication and behavioural therapy for school-aged children with ADHD [1].

\footnotetext{
* Correspondence: mltan@pmc.edu.my

${ }^{1}$ Paediatric Department, Penang Medical College, George Town, Penang, Malaysia Full list of author information is available at the end of the article
}

Medications are effective, but not without problems. Adverse effects of medication, such as gastrointestinal and sleeps disturbances from methylphenidate, are common [4]. In the recently published Cochrane Systematic Review on methylphenidate in children with ADHD, there was a $60 \%$ increase in the risk of sleep problems and $266 \%$ increase in risk of reduced appetite among children taking methylphenidate compared to placebo [5]. In addition, many parents do not wish to 'medicate' their child because they perceive that ADHD is not a 'disease' [6]. behavioural 
therapy on the other hand is time consuming and resource intensive [7]. Therefore it is not surprising many parents seek alternative treatment such as nutritional supplements, elimination diet, herbal treatment, acupuncture and others for their ADHD children [8].

One such nutritional supplement is tocotrienols. Tocotrienols is part of the Natural Vitamin E family. It consists of 4 components-alpha, beta, delta and gamma tocotrienols; also collectively known as tocotrienol-rich fractions (TRF) [9]. It is found in abundance in palm oil and rice bran oil [9]. TRF are potent anti-oxidants especially in the central nervous system [10]. Oxidative stress has been found to be a potential cause of for neuronal damage in several neurodevelopment conditions including ADHD [11]. A meta-analysis of 6 studies found that there is a modest increase in oxidative stress in ADHD children and adults [12]. In addition, several studies had found that with anti-oxidant usage, children with ADHD had better behaviour scores [13-15]. TRF may also work by inhibiting glutamate-induced activation of phospholipase A2 (PLA2) in brain tissue, resulting in better metabolism of polyunsaturated fatty acids (PUFAs) [16]. Abnormal metabolism of PUFAs has been implicated as another cause of ADHD [17].

We conducted a randomized controlled trial to determine if supplementation of TRF compared to placebo had an effect on the symptoms of school going children with ADHD. We also looked at the safety of TRF in these children as well as the correlation between tocotrienol levels and their symptom scores.

\section{Methods}

We conducted a randomized placebo-controlled trial in the Child \& Adolescent Psychiatric Clinic at two hospitals in Penang, Malaysia.

\section{Eligibility and enrolment}

Patient records were screened from February till October 2012. All patients born between 31.12.2000 and 1.1.2006 with the diagnosis of ADHD were invited to participate either directly at the clinic or via a telephone call. The diagnosis of ADHD was made in accordance to the Diagnostic and Statistical Manual of Mental Disorder- IV (DSM-IV) criteria by physicians working in these hospitals using diagnostic interviews [18]. If the patient was on ADHD medication (e.g. methylphenidate or atomoxetine), the dose of the medication had to remain unchanged for at least 3 months before enrolment. Patients with syndromes, inborn errors of metabolism, structural brain lesions, co-existing chronic liver disease and those on concurrent anticoagulants or antiplatelet drugs were excluded. Children who were unable to swallow the capsule were also excluded.

\section{Randomization and allocation concealment}

Computer-generated sequence generation and randomization were performed by an independent person not involved in the trial. Permutated block randomization of unknown size to investigators was used. Allocation concealment was by sequentially numbered sealed opaque envelopes.

\section{Intervention and placebo}

Children were randomized to receive $200 \mathrm{mg}$ of TRF or placebo daily. These were given as 2 softgel capsules daily containing either $100 \mathrm{mg}$ TRF per capsule or placebo (soya bean based cooking oil).

Each $100 \mathrm{mg}$ capsule of TRF (Tocovid Suprabio) contained the following: alpha tocotrienol $30.76 \mathrm{mg}$, gamma tocotrienol $56.40 \mathrm{mg}$, delta tocotrienol $12.84 \mathrm{mg}$, alpha tocopherol $45.80 \mathrm{IU}$, plant squalene $25.64 \mathrm{mg}$, phytosterol complex $10.24 \mathrm{mg}$, phyto-carotenoid complex $180.00 \mathrm{mcg}$.

Blinding of the study personnel, participants and outcome assessors were achieved by identical packaging of both TRF and placebo manufactured by Hovid Bhd. They were similar in size, shape, colour, texture and outer-taste. At the end of the study, the effectiveness of blinding was assessed by asking parents if they could guess what their child received.

The investigators purchased both the TRF and placebo capsules from the manufacturer.

\section{Conduct of study}

All of the children underwent a 1 month run-in with placebo. The children were allowed to continue with their existing ADHD medication. However, those who were taking any over-the-counter nutritional supplements were instructed to discontinue these at the point of entry to the study and throughout the study. They were not informed of the run-in period with placebo. After the run-in period, children were randomized to receive either placebo or TRF. The capsules were dispensed as monthly supplies and they had to return the previous month's bottle. Adherence was assessed by performing pill counts.

At the point of randomization (month 0), the accompanying parent or guardian would complete the NICHQ Vanderbilt ADHD Parent Rating Scale (VAPRS). The NICHQ Vanderbilt ADHD Teacher Rating Scale (VATRS) was given to the children to be handed over to their class teacher. The teachers' scores were collected back using an enclosed addressed and stamped envelope.

The children were then seen at 3 months and 6 months with a repeat VAPRS and VATRS scoring. Their medical records were checked for alterations made to their medications. All adverse events reported during these visits were recorded. The children also had their 
blood taken for tocotrienol levels at recruitment and after 3 and 6 months of the study. (See Fig. 1)

\section{Ethics}

This study was approved by the National Medical Research Ethics Committee, Ministry of Health Malaysia (NMRR No. 6767). Written consent was obtained from the parent or guardian. Each child was told the nature of his or her participation. This study was also registered with ClinicalTrials.gov (NCT01855984).

\section{Outcome measures}

The primary outcome is the mean ADHD symptom score as measured using the NICHQ Vanderbilt ADHD Parent and Teacher Rating Scales (VAPRS \& VATRS). The secondary outcomes were adverse events, reported changes in existing medication and correlation of plasma tocotrienol levels with the ADHD symptom score.

\section{NICHQ Vanderbilt ADHD Parent and Teacher Rating Scale (VAPRS \& VATRS)}

The VAPRS and VATRS were taken from the American Academy of Paediatric ADHD Toolkit $1^{\text {st }}$ Edition 2002 [19]. The psychometric properties of the VAPRS and VATRS have been evaluated and found to be reliable and valid to be used in practice and research [20, 21]. Both these scales were translated into the local language and the translation had been previously tested in a test population showing good internal reliability [22].
These scales are made up of two main components-the 'Inattention' and 'Hyperactivity/Impulsivity' scores. The sum of these is known as the 'Total Symptom Score'. The maximum score for the Total Symptom Score is 54 (maximum 27 points for each of the two components). Higher scores signify more problematic behaviour.

\section{Tocotrienol levels}

Tocotrienol levels were taken for all children and collected in EDTA bottles. Each sample was centrifuged immediately and the plasma frozen at $-20{ }^{\circ} \mathrm{C}$. All samples were transported in frozen state for laboratory analysis not more than 3 months from the date of collection. The plasma concentrations of alpha, gamma and delta-tocotrienols were measured using a validated high-performance liquid chromatographic (HPLC) method with fluorescence detection [23].

\section{Sample size calculation}

There had been no previous studies using TRF for ADHD. Sample size was calculated based on the study "Effect of Supplementation with Polyunsaturated Fatty Acids and micronutrients on learning and behaviour problems associated with child ADHD" using the Total DSM-IV scores from the Conner's Parent Rating Scale [24]. The scale is very similar to the VAPRS. By using the Power and Sample Size Program for T test Version 2.1 with $80 \%$ power and $5 \%$ level of significance, the sample size required was 63 participants for the treatment group and 22 for placebo group [25]. However, we aimed to recruit 80 children in each group in order



Fig. 1 Study Flow Chart 
to have a balanced ratio and to account for $20 \%$ dropout rate.

\section{Statistical analysis}

All analysis was done based on intention-to-treat (ITT) principle. We used ANOVA repeated measure analysis to compare the mean VAPRS and VAPRS at baseline, 3 months and 6 months. Missing data was handled by interpolating values (for VAPRS) and iterative Markov chain Monte Carlo (MCMC) method (for VATRS).
Categorical data were analysed using Chi square test. Correlation between tocotrienol levels and VAPRS Total Symptom Scores were done using Spearman Rho's. Statistical analyses were done using SPSS Version 22 [26] and Stata Version 12 [27].

\section{Results}

Between February and October 2012, a total of 158 children (134 boys) were enrolled into the study. The mean age of the children was 9.3 years (SD 1.8, minimum 5.4

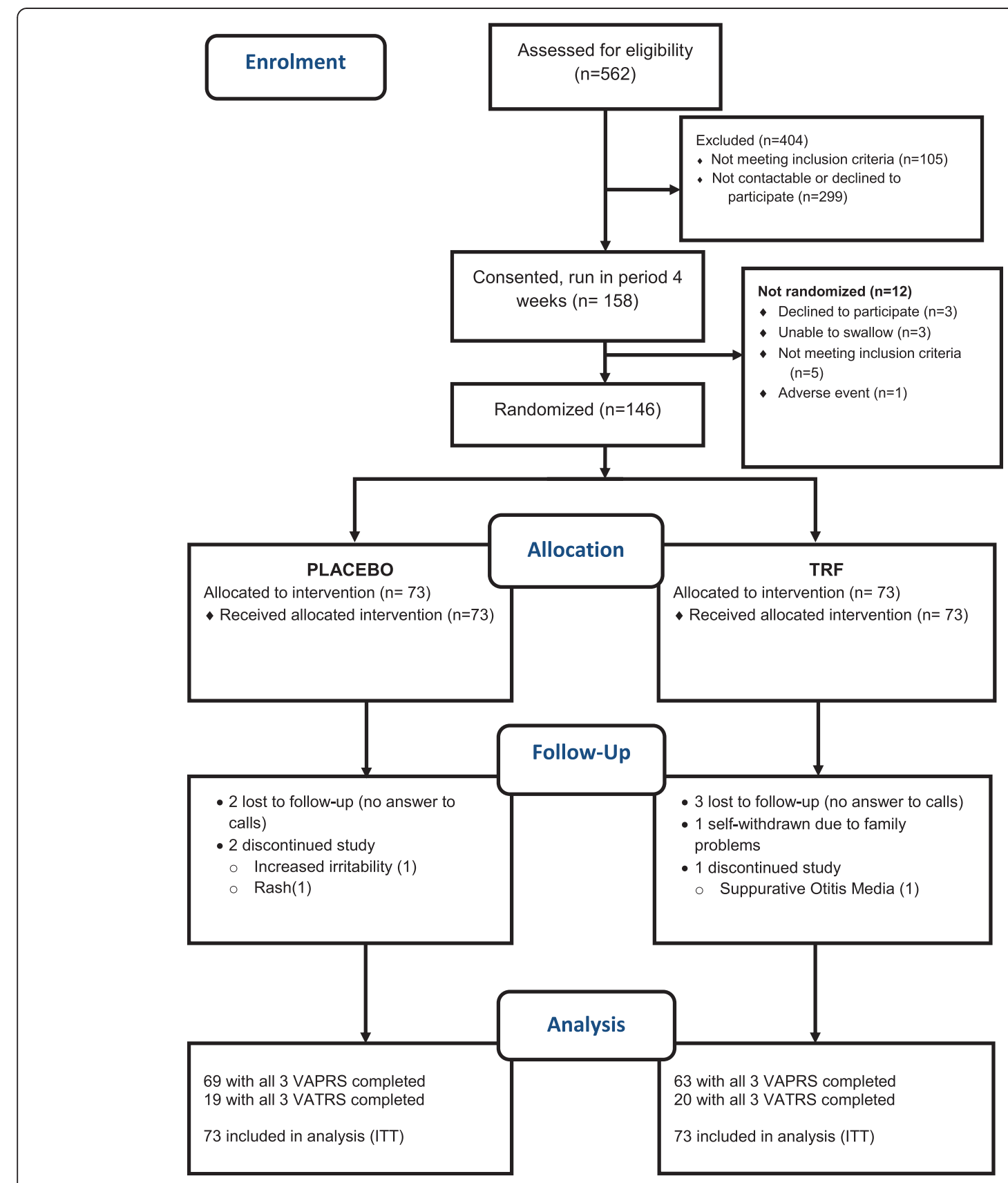

Fig. 2 CONSORT Flowchart 
years, maximum 12.5 years). 12 children did not go on to randomization after the initial run in with placebo, leaving 146 who were randomized. After randomization, 9 did not complete the study: 5 dropped out of the study without reasons, 1 self-withdrew and 3 others were stopped because of adverse events, not related to the intervention (see Fig. 2).

The baseline characteristics of the two groups of children who were randomized were similar (Table 1). The teachers' response rate throughout the study was very poor. At baseline, only 95 (65\%) children had their teacher's score returned.

Primary outcome 1: effect on the parent score (VAPRS) at 3 months and 6 months

The VAPRS Total Symptom Score showed significant reduction over time from baseline to 3 months for both groups $(p=<0.001)$. There was a further reduction from 3 months to 6 months for the placebo group but not the TRF group. However, there was no statistically

Table 1 Baseline characteristics of all the children in the study

\begin{tabular}{llll}
\hline & $\begin{array}{l}\text { Placebo } \\
n=73\end{array}$ & TRF $n=73$ & $p$ value \\
\hline Age in years (mean, SD) & $9.4(1.7)$ & $9.4(1.9)$ & 0.854 \\
Male: Female ratio & 61 male: & 63 male: & 0.644 \\
& 12 female & 10 female &
\end{tabular}

Education Type $(n)$

\begin{tabular}{|c|c|c|c|}
\hline Mainstream & 58 & 56 & 0.689 \\
\hline Special education & 13 & 15 & \\
\hline Others & 2 & 2 & \\
\hline \multicolumn{4}{|l|}{ Parental Education ( $n$ ) } \\
\hline None/Primary & 7 & 9 & 0.866 \\
\hline Secondary & 46 & 45 & \\
\hline Tertiary & 20 & 19 & \\
\hline \multicolumn{4}{|l|}{ ADHD subtypes (n) } \\
\hline Inattentive & 9 & 8 & 0.796 \\
\hline Combined & 64 & 65 & \\
\hline $\begin{array}{l}\text { Presence of comorbid } \\
\text { conditions }(n)\end{array}$ & 30 & 26 & 0.496 \\
\hline Medication for ADHD (n) & 35 & 43 & 0.184 \\
\hline $\begin{array}{l}\text { Mean Baseline VAPRS total } \\
\text { symptom score (SD) }\end{array}$ & $28.97(9.37)$ & $28.91(10.37)$ & 0.976 \\
\hline $\begin{array}{l}\text { Mean Baseline VATRS total } \\
\text { symptom score (SD) }\end{array}$ & $25.83(10.35)^{a}$ & $25.40(10.55)^{a}$ & 0.844 \\
\hline \multicolumn{4}{|l|}{$\begin{array}{l}\text { Baseline tocotrienol levels } \\
\text { (Median) }\end{array}$} \\
\hline Delta (ng/ml) & 9.900 & 10.050 & 0.967 \\
\hline Gamma (ng/ml) & 43.30 & 48.40 & 0.709 \\
\hline Alpha (ng/ml) & 24.60 & 26.40 & 0.935 \\
\hline
\end{tabular}

significant difference between the groups at either time point $(p=0.716)$ (see Table 2 and Fig. 3 ).

When we adjusted the VAPRS Total Symptom Scores to age, gender, parent education or compliance to study intervention, we found a significant effect of age on the mean scores over time $(p=0.02)$ but there was no difference between the groups $(p=0.744)$. Children older than 9 years had the largest change. None of the other factors contributed to the VAPRS Total Symptom Score.

\section{Primary outcome 2: effect on the teacher score (VATRS) at 3 months and 6 months}

Between 35 and $52 \%$ of teacher-reported scores collected at 3 different time points during the trial were missing. The number of missing VATRS was equal between the groups. Only 19 and 20 children in the placebo and TRF group respectively had all 3 VATRS returned. Because the VATRS were missing at random, we performed imputation using Markov chain Monte Carlo (MCMC) method. The following results are based on imputed data.

The VATRS Total Symptom Score showed significant reduction over time from baseline to 3 months for both groups $(p=<0.001)$. The TRF group had a slightly greater reduction in the score over time compared to the placebo group but this was not statistically significant $(p=0.07)$ (see Table 3 and Fig. 3).

\section{Secondary outcomes}

Both groups had no statistically significant difference in the number of children requiring a change in their ADHD medications: three children in the placebo group and six in the TRF group needed increased medications $(p=0.3)$. One child in the placebo group and two children in the TRF group had their medications decreased $(p=0.6)$.

The children in the placebo group had slightly more adverse events reported during the study compared to TRF group. However, this was not statistically significant $(p=0.5)$ (See Table 4). All adverse events reported were trivial and unlikely to be related to the study intervention. The unwanted behaviour reported were mostly temper tantrums which are common in ADHD.

\section{Tocotrienol levels}

Tocotrienol levels were sampled at baseline, 3 months and 6 months after intervention for all children. At baseline, the levels were similar in both groups but at 3 months and 6 months, the TRF group had statistically significant higher levels of delta, gamma and alpha tocotrienols compared to placebo (Fig. 4). However, due to the timing of blood sampling and relatively short halflife of tocotrienols, most of the children did not have levels as high as reported in literature [28]. 
Table 2 Mean VAPRS scores at baseline, 3 months and 6 months

\begin{tabular}{|c|c|c|c|c|c|c|c|c|c|c|c|c|c|c|}
\hline \multirow[t]{3}{*}{ VAPRS (Parent) } & \multicolumn{12}{|c|}{ Mean score } & \multirow{3}{*}{$\begin{array}{l}p \text { value } \\
\text { (time) }\end{array}$} & \multirow{3}{*}{$\begin{array}{l}p \text { value } \\
\text { (treatment }\end{array}$} \\
\hline & \multicolumn{4}{|l|}{ Baseline } & \multicolumn{4}{|c|}{ At 3 months } & \multicolumn{4}{|c|}{ At 6 months } & & \\
\hline & $\begin{array}{l}\text { Placebo } \\
(n=73)\end{array}$ & SD & $\begin{array}{l}\text { TRF } \\
(n=73)\end{array}$ & SD & $\begin{array}{l}\text { Placebo } \\
(n=73)\end{array}$ & SD & $\begin{array}{l}\text { TRF } \\
(n=73)\end{array}$ & SD & $\begin{array}{l}\text { Placebo } \\
(n=73)\end{array}$ & SD & $\begin{array}{l}\text { TRF } \\
(n=73)\end{array}$ & SD & & \\
\hline Total symptoms score & 28.97 & 9.37 & 28.91 & 10.37 & 24.36 & 9.12 & 24.63 & 9.04 & 23.16 & 8.43 & 24.41 & 9.78 & $<0.001$ & 0.716 \\
\hline Inattention score & 15.01 & 4.85 & 14.75 & 4.87 & 12.66 & 4.54 & 12.59 & 4.66 & 11.88 & 4.14 & 12.57 & 4.94 & $<0.001$ & 0.858 \\
\hline Hyperactivity/Impulsivity score & 13.95 & 5.74 & 14.30 & 6.15 & 11.71 & 5.36 & 12.04 & 5.22 & 11.06 & 4.89 & 11.83 & 5.80 & $<0.001$ & 0.541 \\
\hline
\end{tabular}

We used Spearman's Rho correlation to determine if the delta, gamma and alpha tocotrienol levels at 6 months correlated with the change in VAPRS at 6 months. A small but statistically significant correlation was seen between alpha and gamma tocotrienol levels with the change in the VAPRS Total Symptom Score and Inattention Score at 6 months (Table 5).

\section{Adherence to treatment}

Generally children in the TRF group only took $76 \%$ of the capsules dispensed compared to $86 \%$ in the placebo group and this was much lower in the last 3 months of the study compared to the beginning. This could be because TRF have an unpleasant taste and some of the participants bite into the capsule before swallowing them.

\section{Discussion}

This study did not show any difference in the effect of TRF supplementation over placebo on the symptoms of ADHD as measured on the VAPRS and VATRS. To our knowledge this is the first study investigating the effects of TRF in children with ADHD. It is interesting to find that regardless of which group the children were randomized to, all parents reported improvement in their children's behaviour after 3 and 6 months of intervention especially in the first 3 months.

The dose of TRF and duration of supplementation is sufficient and comparable to other studies using the same preparation for a variety of conditions [29, 30]. Therefore, the lack of effectiveness over placebo is not due to these factors.

There are several possibilities for the lack of differences between the two groups. The improvement could have been due to 'placebo effects'. It has been suggested that if we give patients enough attention with a pill to take for their condition, ask them to fill out a questionnaire about their condition and see them in regular intervals, majority would show improvement [31]. We had more frequent contact with parents compared to their regular treatment while participating in this study, as is also seen in other studies [32]. This could in itself be therapeutic, leading to a difference in how the parents view their children's behaviour and subsequently result in an improvement in the children's behaviour. We have attempted to reduce bias by making sure that our allocation and blinding was adequately done. We are certain that there was no way any parent could guess based on the feedback on blinding done at the end of
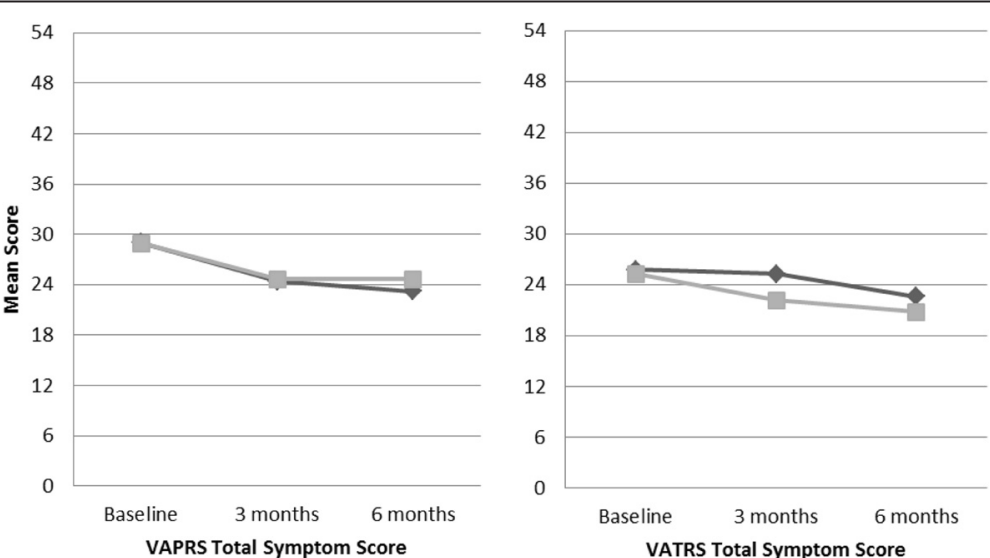

$\multimap$ Placebo - - TRF

Fig. 3 Mean VAPRS and VARTS Total Symptom Score at baseline, 3 months and 6 months 
Table 3 Mean VATRS scores at baseline, 3 months and 6 months

\begin{tabular}{|c|c|c|c|c|c|c|c|c|c|c|c|c|c|c|}
\hline \multirow[t]{3}{*}{ VATRS (Teacher) } & \multicolumn{12}{|c|}{ Mean score } & \multirow[t]{3}{*}{$p$ value (time) } & \multirow{3}{*}{$\begin{array}{l}p \text { value } \\
\text { (treatment) }\end{array}$} \\
\hline & \multicolumn{4}{|l|}{ Baseline } & \multicolumn{4}{|c|}{ At 3 months } & \multicolumn{4}{|c|}{ At 6 months } & & \\
\hline & $\begin{array}{l}\text { Placebo } \\
(n=73)\end{array}$ & SD & $\begin{array}{l}\text { TRF } \\
(n=73)\end{array}$ & SD & $\begin{array}{l}\text { Placebo } \\
(n=73)\end{array}$ & SD & $\begin{array}{l}\text { TRF } \\
(n=73)\end{array}$ & SD & $\begin{array}{l}\text { Placebo } \\
(n=73)\end{array}$ & SD & $\begin{array}{l}\text { TRF } \\
(n=73)\end{array}$ & SD & & \\
\hline Total symptoms score & 25.76 & 10.34 & 25.26 & 10.54 & 25.27 & 10.27 & 22.13 & 10.20 & 22.59 & 10.08 & 20.75 & 10.03 & $<0.001$ & 0.075 \\
\hline Inattention score & 13.86 & 5.51 & 13.65 & 5.35 & 13.98 & 5.42 & 12.33 & 5.67 & 12.21 & 5.00 & 11.48 & 5.46 & $<0.001$ & 0.116 \\
\hline $\begin{array}{l}\text { Hyperactivity/ } \\
\text { Impulsivity score }\end{array}$ & 11.90 & 6.58 & 11.61 & 6.17 & 11.29 & 6.86 & 9.8 & 5.48 & 10.38 & 6.78 & 9.27 & 5.78 & $<0.001$ & 0.131 \\
\hline
\end{tabular}

Footnote: Analysis based on imputed data

the study. Over $50 \%$ of parents in both groups thought their children were receiving TRF and only a minority (2-3\%) within each group thought they had received placebo.

Another reason for this apparent lack of effectiveness over placebo was the choice of outcome measure used. The VAPRS was designed to capture the core symptoms of ADHD comprising of inattention, hyperactivity and impulsiveness. It is also a self-administered score and parent's knowledge and perception about their child's behaviour could influence how they report the score [33]. We found that the parents of our participants had difficulty quantifying their children's behaviour to the scale within the VAPRS. They were more able to describe the changes in behaviour verbally or with a free text questionnaire. We firmly believe that there could be other aspects of improvement in the child because when we reviewed our end-of-study questionnaire, we found some objective responses from parents of children in the TRF group. Most of these relate to academic improvement and increase in duration of concentration. It is possible that TRF had no effect on the core symptoms of ADHD, but on other aspects not captured in our outcome measure.

It was difficult to interpret the VATRS because many of the teachers did not return the scales. Teachers' responses are likely to be more objective compared to parents' scores. However, they may not be as observant as parents especially when they have a large number of children in the class. Similar

Table 4 Adverse events reported

\begin{tabular}{|c|c|c|c|}
\hline & Placebo & TRF & \\
\hline Gastrointestinal Disturbances & 3 & 1 & \\
\hline Fatigue & 1 & 0 & \\
\hline Unwanted behaviour Changes & 5 & 5 & \\
\hline Epistaxis & 1 & 0 & \\
\hline Rash & 2 & 0 & \\
\hline $\begin{array}{l}\text { Others (Infections, curly hair, chest pain, } \\
\text { pimples, dry lips, fractured metatarsal } \\
\text { due to road accident, headache) }\end{array}$ & 12 & 8 & \\
\hline Total & 24 & 14 & $p$ value $=0.57$ \\
\hline
\end{tabular}

problems with teachers had been reported in another study [24]. We found that the teachers reported better scores in the TRF group compared with the placebo group after 6 months but the difference between the groups did not reach statistical significance. However, it must be noted that this finding was seen in the analysis with imputed data. If we could have complete data, we might be able to be more certain about this finding.

Although there was statistically significant correlation between increase in alpha and gamma tocotrienol levels with a greater change in score, the correlation was very small. Again, this can be attributed to the fact that all reported improvement regardless of the group allocation.

Finally, it would be incomplete if we did not consider the possibility that the intervention may have been too late. There is evidence that dysregulated plasticity in the developing brain is related to ADHD [34]. Newer studies on nutrition are shifting to supplementing population at risk to see if it will help prevent the condition. One such study is the one using alpha tocopherols in extremely low birthweight babies and the findings suggest that it does change their behaviour outcomes [35].

Last but not least, TRF use is generally safe in children. We did not encounter any major adverse events and most of what was reported were unlikely related to the intervention.

\section{Conclusion}

This study was unable to demonstrate that TRF was better than placebo in reducing ADHD symptoms as reported by parent's and teacher's scores. However, there is a possibility that academic performances of these children could be improved by the use of TRF.

In order to fully investigate the role of TRF in treatment of children with ADHD, further studies should be conducted using an objective outcome measurement (especially measuring attention-span) in addition to the parent's or teacher's reports as well as investigating the effect of TRF in the 'at risk' population in early life even before they developed any symptoms. 


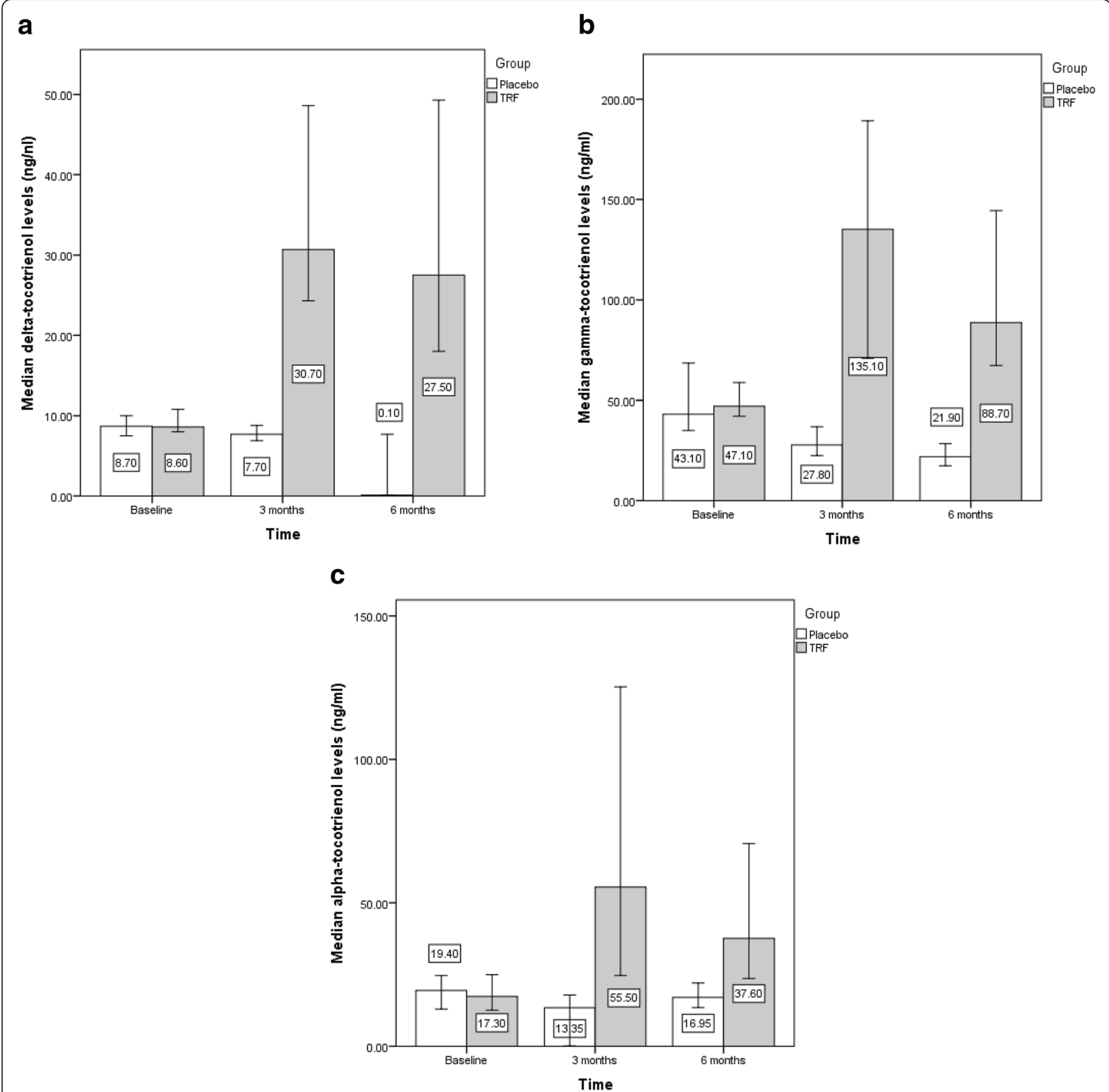

Fig. 4 a, b, c Serum delta, gamma and alpha-tocotrienol levels according to groups at baseline, 3 months and 6 months for participants with complete dataset (placebo group: $n=68$, TRF group: $n=65$ )

Table 5 Correlation between tocotrienol levels with change from baseline in VAPRS after 6 months

\begin{tabular}{|c|c|c|c|c|c|c|}
\hline & \multicolumn{2}{|c|}{$\begin{array}{l}\text { Change in VAPRS Total } \\
\text { Symptom Score after } 6 \text { months }\end{array}$} & \multicolumn{2}{|c|}{$\begin{array}{l}\text { Change in VAPRS Inattention } \\
\text { Score after } 6 \text { months }\end{array}$} & \multicolumn{2}{|c|}{$\begin{array}{l}\text { Change in VAPRS Hyperactive/Impulsivity } \\
\text { Score after } 6 \text { months }\end{array}$} \\
\hline & Correlation Coefficient & $\overline{p \text { value }}$ & Correlation Coefficient & $\overline{p \text { value }}$ & Correlation Coefficient & $p$ value \\
\hline Delta-tocotrienol & 0.106 & 0.2 & 0.133 & 0.1 & 0.051 & 0.5 \\
\hline Gamma- tocotrienol & 0.193 & 0.02 & 0.202 & 0.01 & 0.148 & 0.07 \\
\hline Alpha- tocotrienol & 0.184 & 0.03 & 0.167 & 0.05 & 0.139 & 0.09 \\
\hline
\end{tabular}




\section{Abbreviations}

ADHD: Attention Deficit/Hyperactive Disorder; DSM-IV: Diagnostic and Statistical Manual of Mental Disorder-IV; ITT: Intention-to-treat; MCMC: Markov chain Monte Carlo; TRF: Tocotrienol-rich fractions; VAPRS: NICHQ Vanderbilt ADHD Parent Rating Scale; VATRS: NICHQ Vanderbilt ADHD Teacher Rating Scale.

\section{Competing interests}

The authors declare that they have no competing interests.

\section{Authors' contribution}

MLT, SCF, WCF and YY conceptualized the study design, participated in collection of data, analysed the data and interpreted the data. SMC participated in collection of data and interpretation of data. MLT and SCF wrote the manuscript with comments from WCF and SMC. All authors had read and approved of the final manuscript.

\section{Acknowledgements}

This study was funded by Performance Management and Delivery Unit, Prime Minister's Department, Malaysia (PEMANDU) \& Malaysian Palm Oil Board (MPOB). The funders had no role in developing the study protocol, data collection, analysis or interpretation of the results.

The authors would like to thank the Director General of Health, Malaysia for permission to publish this paper

We also thank Zohreh Toghrayee from Universiti Sains Malaysia for additional statistical analysis.

\section{Author details}

${ }^{1}$ Paediatric Department, Penang Medical College, George Town, Penang, Malaysia. ${ }^{2}$ Child \& Adolescent Psychiatry, Hospital Sultan Abdul Halim, Sungai Petani, Kedah, Malaysia. ${ }^{3}$ Clinical Psychologist, Dean's Office, Penang Medical College, George Town, Penang, Malaysia.

\section{Received: 28 October 2015 Accepted: 24 February 2016}

\section{Published online: 21 March 2016}

\section{References}

1. Subcommittee on Attention-Deficit/Hyperactive Disorder, Steering Committee on quality improvement and management. ADHD: Clinical Practice Guideline for the Diagnosis, Evaluation, and Treatment of Attention-Deficit/Hyperactive Disorder in Children and Adolescents. Pediatrics. 2011;128(5):1007-22.

2. Brown RT, et al. Prevalence and assessment of attention-deficit/hyperactivity disorder in primary care settings. Pediatrics. 2001;107(3):E43.

3. Hoagwood K, et al. Treatment services for children with ADHD: a national perspective. J Am Acad Child Adolesc Psychiatry. 2000;39(2):198-206.

4. Charach A, Ickowicz A, Schachar R. Stimulant treatment over five years: adherence, effectiveness, and adverse effects. J Am Acad Child Adolesc Psychiatry. 2004:43(5):559-67.

5. Storebo OJ, et al. Methylphenidate for children and adolescents with attention deficit hyperactivity disorder (ADHD). Cochrane Database Syst Rev. 2015;11:CD009885

6. Charach $\mathrm{A}$, et al. Using stimulant medication for children with ADHD: what do parents say? A brief report. J Can Acad Child Adolesc Psychiatry. 2006;15(2):75-83.

7. Telford $\mathrm{C}$, et al. Estimating the costs of ongoing care for adolescents with attention-deficit hyperactivity disorder. Soc Psychiatry Psychiatr Epidemiol. 2013;48(2):337-44

8. Weber W, Newmark S. Complementary and alternative medical therapies for attention-deficit/hyperactivity disorder and autism. Pediatr Clin North Am. 2007;54(6):983-1006. xii.

9. Sen CK, Khanna S, Roy S. Tocotrienols in health and disease: the other half of the natural vitamin E family. Mol Aspects Med. 2007;28(5-6):692-728.

10. Serbinova EA, Packer L. Antioxidant properties of alpha-tocopherol and alpha-tocotrienol. Methods Enzymol. 1994;234:354-66.

11. Ng F, et al. Oxidative stress in psychiatric disorders: evidence base and therapeutic implications. Int J Neuropsychopharmacol. 2008;11(6):851-76.

12. Joseph N, et al. Oxidative Stress and ADHD: A Meta-Analysis. J Atten Disord. 2015;19(11):915-24.

13. Trebaticka J, et al. Treatment of ADHD with French maritime pine bark extract, Pycnogenol. Eur Child Adolesc Psychiatry. 2006;15(6):329-35.

14. Katz $\mathrm{M}$, et al. A compound herbal preparation (CHP) in the treatment of children with ADHD: a randomized controlled trial. J Atten Disord. 2010;14(3):281-91.
15. Zhou R, Han X, Wang J, Sun J. Baicalin may have a therapeutic effect in attention deficit hyperactivity disorder. Medical hypotheses. 2015;85(6):761-4.

16. Khanna S, et al. Nanomolar vitamin E alpha-tocotrienol inhibits glutamateinduced activation of phospholipase A2 and causes neuroprotection. J Neurochem. 2010;112(5):1249-60.

17. Stevens $\sqcup$, et al. Omega-3 fatty acids in boys with behavior, learning, and health problems. Physiol Behav. 1996;59(4-5):915-20.

18. Diagnostic and Statistical Manual of Mental Disorders, Fourth Edition, Text Revision (DSM IV-TR). 2000, Arlington: American Psychiatric Association

19. NICHQ. Caring for Children with ADHD: A Resource Toolkit for Clinicians (1st Edition). 2002; http://www.nichq.org/childrens-health/adhd/resources/ adhd-toolkit. Accessed 17 April 2012

20. Bard DEP, et al. The Psychometric Properties of the Vanderbilt AttentionDeficit Hyperactivity Disorder Diagnostic Parent Rating Scale in a Community Population. Journal of Developmental \& Behavioral Pediatrics. 2013;34(2):72-82.

21. Wolraich MLMD, et al. The Psychometric Properties of the Vanderbilt Attention-Deficit Hyperactivity Disorder Diagnostic Teacher Rating Scale in a Community Population. Journal of Developmental \& Behavioral Pediatrics. 2013;34(2):83-93.

22. Md Nasir N, Mohd Shahidi R, Ab Rahman A, Othman A. A Preliminary Study on the Reliability of the Malay Version of the National Initiative for Children's Healthcare Quality (NICHQ) Vanderbilt Assessment Scale: Parent and Teacher Informant among School Children in Kelantan, Malaysia, Poster presentation, 6th National Pediatrics Research Conference Universiti Sains Malaysia. 2013

23. Yap SP, et al. Simple high-performance liquid chromatographic method for the determination of tocotrienols in human plasma. J Chromatogr B Biomed Sci Appl. 1999;735(2):279-83.

24. Sinn N, Bryan J. Effect of supplementation with polyunsaturated fatty acids and micronutrients on learning and behavior problems associated with child ADHD. J Dev Behav Pediatr. 2007;28(2):82-91.

25. Dupont W, Plummer W. Power and sample size calculations: A review and computer program. Controlled Clinical Trials. 1990;11:116-28.

26. IBM Corp. IBM SPSS Statistics for Windows, Version 22.0. Armonk: IBM Corp; 2013.

27. StataCorp. Stata Statistical Software: Release 12. College Station: StataCorp LP; 2011.

28. Yap SP, Yuen KH, Wong JW. Pharmacokinetics and bioavailability of alpha-, gamma- and delta-tocotrienols under different food status. J Pharm Pharmacol. 2001;53(1):67-71.

29. Beoy LA, Woei WJ, Hay YK. Effects of tocotrienol supplementation on hair growth in human volunteers. Trop Life Sci Res. 2010;21(2):91-9.

30. Nesaretnam $\mathrm{K}$ et al. Effectiveness of tocotrienol-rich fraction combined with tamoxifen in the management of women with early breast cancer: a pilot clinical trial. Breast Cancer Research. 2010;12(5):R81

31. Arnold LE. Placebo response and the company it keeps. JAMA Pediatr. 2013; 167(11):1000-1.

32. Perera $\mathrm{H}$, et al. Combined $\omega 3$ and $\omega 6$ Supplementation in Children With Attention-Deficit Hyperactivity Disorder (ADHD) Refractory to Methylphenidate Treatment. J Child Neurol. 2012;27(6):747-53.

33. Xiao ZH, et al. Diagnostic value of Vanderbilt ADHD Parent Rating Scale in attention deficit hyperactivity disorder. Zhongguo Dang Dai Er Ke Za Zhi. 2013;15(5):348-52

34. Liston C, et al. Atypical prefrontal connectivity in attention-deficit/ hyperactivity disorder: pathway to disease or pathological end point? Bio Psychiatry. 2011;69(12):1168-77.

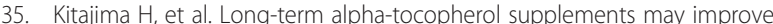
mental development in extremely low birthweight infants. Acta Paediatr. 2015;104(2):e82-9. 